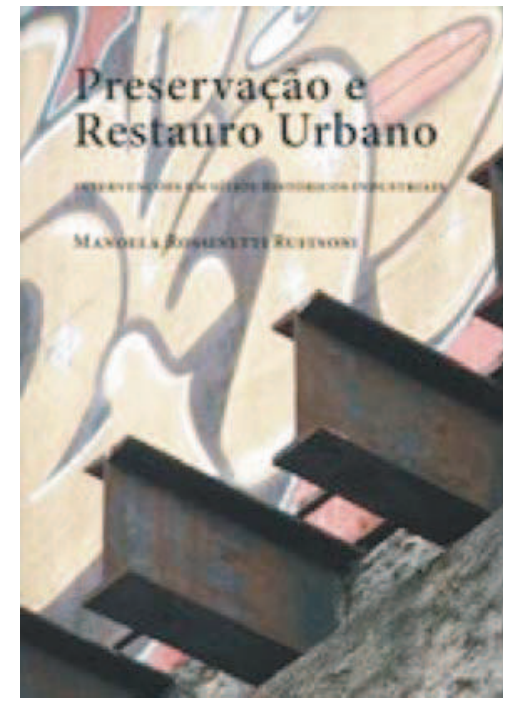

Júlio Roberto Katinsky
Preservação e restauro URBANO - INTERVENÇÕES EM SÍTIOS HISTÓRICOS INDUSTRIAIS

RUfinoni, Manoela R. São Paulo: Editora FAP/ Unifesp/ Edusp, 2013.

\title{
ESTUdO HISTÓRICO DE CONJUNTOS URBANOS
}

O estudo da professora Manoela Rossinetti Rufinoni apresenta-se como um apanhado histórico-crítico dos conjuntos urbanos a serem preservados, como bens culturais imprescindíveis à conservação da memória coletiva das cidades, face às inevitáveis transformações que estas vêm sofrendo ao longo de sua história, mas especialmente as cidades de nossa recente instalação industrial. Assim, o livro em questão define-se em duas partes complementares.

1) A Preservação Urbana e o contraponto da cidade industrial.

2) O Restauro Urbano e o espaço industrial como Artefato Cultural.

A primeira parte é composta também de duas:

1.1 A maturação do conceito de Patrimônio Urbano

1.2 O Patrimônio Urbano em cena: preservação e intervenção.

Esses dois capítulos, por assim dizer, subdividem-se nos seguintes títulos:

1.1 A maturação do conceito de Patrimônio Urbano

1.1.1 Os espaços da indústria impulsionam o debate

1.1.2 Interpolações em um texto

1.1.3 Ambiente, monumento, valor: conceitos em formação

1.1.4 As contribuições da nascente disciplina do urbanismo

1.20 Patrimônio Urbano em cena: preservação e intervenção

1.2.1 Reflexão sobre a relação "antigo - novo"

1.2.2 A dimensão urbana da preservação e do restauro

1.2.3 Os documentos internacionais e a expansão do patrimônio cultural

1.2.4 A apresentação do patrimônio urbano no contexto brasileiro 
No item 1.1.1, a autora discute as preocupações com a preservação das edificações urbanas nas cidades europeias, à luz dos estudos feitos (de preferência) nos séculos 19 e 20, mas com ênfase em extensa bibliografia elaborada no século passado. Assim, na página 29, a autora afirma:

A partir de diferentes pontos de vista que mantêm as cidades como centro de discussão, o desenvolvimento de estudos em ambos os campos disciplinares - o restauro e o urbanismo - oferecer-nos-á, ao longo dos séculos 19 e 20, os instrumentos conceituais e operativos que delinearão a ideia de patrimônio urbano.

Sem dúvida, a cidade é o palco e o objeto das discussões da cultura no século 19. Mas parece-nos que o âmbito da transformação das cidades europeias, principalmente Paris e Londres, estava vincado pelas novas relações sociais, pelas novas condições de exercício da cidadania. É o que se nota na literatura dos românticos, seja Schiller, sejam Victor Hugo ou Stendhal, ou ainda Manzoni. O surgimento de um proletariado urbano vivendo em condições miseráveis nas cidades inglesas, o Terror visto como produto direto da barbárie instalada pela Revolução Industrial, ocupou as mentes da maioria dos intelectuais europeus, na primeira metade do século 19. Só na segunda metade, depois das grandes obras de Paris, realizadas principalmente sob Napoleão III, a ideia de uma possível harmonização entre as transformações técnicas e sociais e o patrimônio herdado, este mesmo criticamente considerado, começa a ser elaborada, mas é óbvio que nunca se pensou em conservar as cidades, construídas quase como se fossem uma multiplicação cancerígena, local privilegiado das epidemias arrasadoras e desconhecidas no passado remoto.

Em 1.1.2, "Interpolações em um texto", a autora se detém, apoiada em Paolo Portoghesi, no pensamento de Alberti, de onde emerge uma preocupação com a conservação da memória urbana (p. 32 e 33). No entanto Florença, ao tempo de Alberti, era uma cidade de cerca de 100 mil pessoas, uma das maiores cidades italianas da época, cuja origem remonta a um pequeno castro romano. De fato, nesses mil anos, o que sobrou da cidade romana? Um conjunto de ruas que se cruzavam e que, em fotografia aérea, ainda é perceptível na cidade. No século 20, foram feitas escavações sob o piso da nave da igreja Santa Maria Del Fiore e, além de descobrirem um túmulo, que se supõe ser o de Brunelleschi, foram descobertas ruínas dos alicerces de casas romanas, o que nos permite supor que elas sobreviveram ainda no tempo da igreja de Santa Reparata, aquela anterior a Santa Maria. Mas também, observando a planta da cidade, podemos estimar que a catedral de Florença ocupa quase um terço da antiga cidade romana. E podemos também reconhecer que o atual "centro histórico" de Florença é, em grande parte, posterior a 1400, subsistindo somente alguns edifícios religiosos, como o convento de São Marcos ou a "Santa Croce". Como, aliás, as outras cidades italianas, cujos "centros históricos" não são, em parte, mais antigos do que 1200 ou 1300. Nada, ou quase nada, subsistiu das cidades romanas. Em compensação, podemos dizer que a "moldura" dessas igrejas mais importantes é constituída pelas casas das pessoas gradas da cidade, testemunho da riqueza italiana resultante do intenso comércio que se desenvolvia pela posição privilegiada da península italiana, a meio caminho, no Mediterrâneo, entre a Europa do norte e os países do Oriente Médio e o norte da África. 
O titulo seguinte, (1.1.3) "Ambiente, monumento, valor: conceitos em formação", estuda o desenvolvimento desses conceitos, de acordo com seu relacionamento com o ambiente urbano, ao longo dos séculos 19 e 20, especialmente pela contribuição de Ruskin e Morris, na Inglaterra, e Carlo Cattaneo e Camillo Boito, na Itália, no século 19, e de Alois Riegl e Max Dvorak, no século 20, na Áustria.

A parte seguinte (1.1.4) estuda as contribuições das reflexões sobre a cidade e as intervenções para viabilizar a cidade industrial e as necessidades sociais emergentes nos séculos precedentes àqueles mais detalhados, ou seja, séculos 19 e 20.

1.2 "O Patrimônio Urbano em cena: Preservação e intervenção."

(1.2.1) O livro prossegue, apresentando o "conflito" entre o antigo e o novo no ambiente urbano, a partir da preservação dos monumentos singulares, de uma "história" pelo menos milenar (como as pirâmides do Egito, ou os templos gregos) e sua "moldura", por assim dizer, derivando para uma noção mais abrangente de "ambientes urbanos", como expressão global de uma época, ou de um monumento da história de uma comunidade. Assim, temos a proteção, desde o século 15, na Itália, dos núcleos centrais de suas cidades, caracterizada por diplomas legais. E também por uma discussão pública que atinge, como o trabalho mostra, os séculos 19 e 20, em que se discute não só o presente, mas o próprio futuro das cidades. É o que detalham os capítulos (1.2.2) "A dimensão urbana na preservação e no restauro" e (1.2.3) "Os documentos internacionais e a expansão do patrimônio cultural". Mas a discussão não se afasta do modelo "obra de arte", subjacente a toda a discussão sobre o novo conceito implícito de "monumento", que sempre conservou o significado primitivo da palavra, ou seja, os "monumentos" sempre foram, em nossa cultura, construídos como "obras de arte", para perenizar fatos históricos relevantes.

Finalmente, esta primeira parte finaliza com o pequeno capítulo (1.2.4) "A apresentação do Patrimônio Urbano no contexto brasileiro". Esse, nos parece, o capítulo mais fraco do livro, na medida em que apresenta tudo o que ocorreu aqui como mero reflexo do que aconteceu fora. Não há dúvida de que toda a vida cultural brasileira girou em torno de contribuições externas, até mesmo a valorização romântica da arte popular, caracterizada como "folk-lore".

Não há dúvida (e nem podia haver) de que os modernistas foram os que primeiro perceberam a absoluta necessidade de utilizar os instrumentos do Estado para garantir a preservação das obras significativas da arte no Brasil. Mas isso não invalida o registro, também no Brasil, de um despertar próprio, como os esforços de José Mariano Filho, ou Paulo Duarte, por exemplo, entre muitos outros, pela preservação de obras aqui construídas. Também os critérios de preservação foram tão elásticos, que, já em 1937, essa consciência crítica se fixou na proteção da mais humilde "aldeia de Carapicuíba", um conjunto de casas de pau-a-pique, extremamente precárias, e uma capela do século 18, de taipa, pela luta desinteressada de tantos intelectuais brasileiros. Também as primeiras instalações industriais (engenhos e "armações de baleias") mereceram a atenção dos estudiosos seguidores das diretrizes do Serviço do Patrimônio Histórico e Artístico Nacional (SPHAN).

Há, pois, toda uma história a ser recuperada, o que esse capítulo não inicia, por sua fixação na ideia de tudo relatar como se a conservação do 
patrimônio brasileiro fosse uma simples transposição do que ocorreu na Europa e Estados Unidos.

A segunda parte, sob o título (2) "O restauro urbano e o espaço industrial como artefato cultural", mostra as discussões para o estabelecimento de uma visão crítica rigorosa, sobre a preservação e o restauro do patrimônio urbano industrial, tanto na Europa como no Brasil, mas essa discussão longe está de ser conclusiva. Isso, porque, em primeiro lugar, não se estabeleceram critérios positivos para a coleta e conservação dos produtos industriais, que se confundem com a história da técnica de maneira geral. Essa história da técnica não se restringe aos últimos séculos de nossa história, e nem mesmo ao período em que universalmente se reconhece a emergência da obra de arte. Para muitos antropólogos, a emergência e conservação dos instrumentos líticos é o primeiro sinal, mais convincente, da separação entre hominídeos (homo habilis) e os grandes antropoides. Mas não se pretendem expor, nos museus de história da técnicas, todas os "machados de mão" até agora encontrados, nem todos os produtos da chamada "Revolução Industrial" (quantos aparelhos de tomografia devem ser conservados? Os primeiros ou os de última geração?). Além disso, eles costumam ser grandes. Só alguns produtos da indústria moderna conseguem subsistir. Mesmo um "museu da aeronáutica" subsiste, em alguns exemplares, com modelos reduzidos, inclusive nos países mais ricos e mais empenhados na construção desses museus. Os museus de história da técnica naval, como o de Greenwich ou de Barcelona, são exemplos concretos dessas dificuldades, ou seja, os produtos industriais não são assimiláveis aos conceitos estéticos tradicionais, que guiaram os critérios de preservação dos monumentos de nossa civilização, seja uma pirâmide, um templo grego ou uma igreja barroca.

O mesmo se pode dizer dos galpões industriais: não só muitos deles são exemplares de um mesmo modelo, como são de difícil adaptação a um novo uso, como prova um dos mais bem sucedidos exemplos de "reciclagem" de galpão industrial, a transformação da fabrica de tambores da Vila Pompeia, em São Paulo, em local de lazer, projeto de Lina Bardi (Sesc Pompeia). Apaixonada por uma estrutura interna de concreto (que sustenta as janelas zenitais da antiga fábrica), Lina alterou substancialmente o espaço fabril, multiplicando a luz natural, pelo artifício de substituir telhas de barro por telhas de vidro, pela construção de um espelho d'água (que ela chamou poeticamente de Rio São Francisco), pela inclusão de um mezanino de concreto armado aparente, de evidente referência à estética funcionalista e industrial do movimento modernista, e também pela retirada do revestimento de argamassa das paredes periféricas, tanto do interior como do exterior. As fotografias anteriores às intervenções de Lina Bardi na antiga fábrica de tambores sugerem um espaço escassamente iluminado, pouco higiênico, desagradável mesmo. Nada parecido com o ambiente atual, a ponto de podermos dizer que se trata de um outro espaço. As fábricas que eu conheci na minha adolescência (anos 40) seguiam esse mesmo padrão insalubre. A maior parte dos espaços industriais, de difícil adaptação às nossas exigências atuais de conforto e higiene, para uso constante de novos hábitos, e mesmo novos valores estéticos universalmente reconhecíveis pelos habitantes, condição para serem incorporados ao acervo de bens a serem preservados.

A senhora Rufinoni reproduz as críticas, principalmente italianas, a duas obras de reciclagem: Gênova e Nápoles. Em particular, em Gênova, a destruição 
de lajes do tempo de Colombo, pela construção de um tubo de metrô. Mas essas discussões, por mais valiosas que sejam, não nos fornecem mais que aquilo que sabíamos sobre o patrimônio industrial a ser preservado.

A autora parece se inclinar a uma atitude voluntarista, sugerindo que as universidades não estão cumprindo seu papel, na formação dos profissionais que deveriam ser responsáveis pelo restauro e conservação. Assim, à página 236, registra a opinião de A. M. Racheli:

É que os fatos infelizmente demonstram e isso é em grande parte atribuível aos resultados do ensino universitário, que deixa mão livre aos professores [de projeto] para orientar os alunos na realização de operações de sistemática destruição do ambiente construído, sem mesmo se colocar, preliminarmente, o objetivo de efetuar uma pesquisa prévia digna de tal nome, opta a verificar, ao menos em suposição, se algum edifício por acaso seja merecedor de conservação ou não [...]. A preparação universitária deveria [ao contrário] induzir os estudantes, desde os primeiros anos, a compreender que para operar é necessário primeiro conhecer, e que fazer uma boa arquitetura, como dizia Adolfo Loos, não significa, a todo custo, fazer-se por notar.

A autora parece acreditar que cabe à universidade dirigir e orientar a sociedade civil, quando a história demonstra que cabe à sociedade civil renovar a universidade, quando esta se torna esclerosada, como sua crônica tem demonstrado, ao longo desses mil anos no Ocidente.

Não se pode responsabilizar a universidade pela ausência de uma teoria crítica consistente quanto aos bens que deveriam ser preservados. Mesmo porque a história nos ensina que todo o desenvolvimento científico da Europa dos séculos 17 e 18 se realizou à margem da universidade. Os intelectuais exteriores à universidade foram fundamentais para chamar a atenção para os produtos industriais, como atestam a Grande Enciclopédia de Diderot e D’Alembert. A Enciclopédia, com certeza, é responsável pelos primeiros museus "des Arts et métiers".

Igualmente, a História da Arte, que, como ciência, se firmou ao final do século 19, tem, como precursores, "amadores" não ligados à universidade, como Ghiberti, Vasari, e Bellori.

Não se pode responsabilizar os arquitetos pela destruição de bens que nem sequer foram arrolados pela crítica histórica, aliás, tal crítica é inexistente, nesse caso. Não se pode responsabilizar uma categoria profissional por uma ação que cabe a muitos protagonistas, como filósofos, cientistas, tecnólogos, cientistas sociais e políticos, devidamente orientados para as tarefas de transformação da cidade contemporânea em um local tão aprazível quanto era a cidade do século 13, na Itália, para seus moradores. E, no entanto, epidemias nessas cidades chegaram a dizimar algumas vezes ? da população, mas, ainda assim, não abateram o ânimo de construção urbana nessas mesmas cidades, que atraem hoje multidões de turistas de todo o mundo.

Não se pode, portanto, concordar com a opinião final subscrita pela autora, ao reproduzir a observação de Bonelli, na década de 50: 
Quando virmos os arquitetos recusarem as tarefas profissionais que impliquem destruições dos ambientes antigos, a ruína dos monumentos e alterações da paisagem, uma nova época se iniciará! Esse dia certamente ainda está distante, mas estamos certos de que chegará. (p. 309)

Não deixa de ser relevante lembrar que a cidade de São Paulo, por exemplo, cresceu, de cerca de 200 mil pessoas, em 1890, para 11 milhões de habitantes atualmente. Os problemas da cidade, inclusive a salvaguarda de seu patrimônio, deverão ser resultado de um esforço crítico que estará ancorado na contribuição dos tecnólogos, cientistas, artistas (inclusive arquitetos), paisagistas e demais seres pensantes que habitam essa ou outras cidades modernas. Enquanto isso vai se dando, o livro da professora Rufinoni entra nesse "mainstream" de reflexão sobre a cidade.

SP. $14 / 07 / 2014$

\section{Júlio Roberto Katinsky}

Possui graduação, mestrado e doutorado em Arquitetura e Urbanismo pela Universidade de São Paulo (USP). Atualmente é professor titular da USP e professor orientador no Curso de Pós-Graduação da FAUUSP.

Rua Maranhão, 88 - Higienópolis

01240-000 - São Paulo, Brasil

(11) 3017-3164

jrkatynsky@uol.com.br 